sional societies (chemistry, physics and so on), commercial firms, and even governmental bodies (MEDLARS, INIS). However, the intensified use of such tape stores highlights the serious problems of standardization, incompatibilities of format and indexing vocabularies that are not on speaking terms. From a somewhat passive storage role microfilm is rapidly becoming more active in association with computer technology. Computer Output Microfilm (COM) combines the miniaturization and the handling of records. There are indications of the progressive merging of the publishing industries (with their micro-publishing, bespoke information packages and so on) and some documentation services, since "a totally integrated technology for information transfer" would certainly reduce costs.

Perhaps the three most stimulating chapters, and this lies partly in the nature of the subjects and the critical approach of the authors, are those on information needs and uses (Ben-Ami Lipetz), design and evaluation of information systems (F. W. Lancaster and C. J. Gillespie) and library automation (R. H. Parker). Under evaluation a new term "lexicodynamics" is reported, which expresses "the concept of construction, maintenance, use and change of controlled vocabularies for information retrieval purposes". This is an area which is absorbing a great deal of documentation manpower everywhere. Also there is a useful discussion on the evaluation of published indexes and a basic criterion is suggested-unit cost per useful reference retrieved in relation to the total number examined and the search time needed.

On the mechanization of library processes improvements in both hardware and software have made it possible to work within the traditional bibliographical norms, rather than accepting the earlier machine restrictions. Furthermore, this computerization shows signs of coming of age in that it is now being evaluated objectively rather than emotionally. In the chapter on management information systems S. D. Weiss stresses that "the literature . . . lacks both organization and classification", which some documentalists have long suspected. The explanation given is that this interdisciplinary field consists of a number of disparate subjects.

This volume marks the end of the fiveyear subsidy from the US National Science Foundation, and it now becomes a straight commercial publication. The Review has certainly maintained the good standards it set at the beginningtimeliness, variety and quality of the reviewers, indexes both current and cumulative, though greater depth of indexing would be more helpful.

Herbert Coblans

\section{Brain and Hormones}

Pituitary, Adrenal and the Brain. Edited by D. de Wied and J. A. W. M. Weijnen. (Progress in Brain Research, Volume 32.) Pp. $x v+357$. (Elsevier: Amsterdam, London and New York, 1970.) £9.

THIS volume covers the proceedings of an international conference on the pituitary-adrenal axis and the nervous system, held at Vierhouten, the Netherlands, in 1969. Each of the forty-two chapters is followed by worthwhile discussion.

The first part of the book covers the first session of the conference and provides details of the latest research on the effect of the nervous system on pituitary-adrenal activity. Present views of feedback control of adrenal steroids on the hypothalamus are given, and some interesting discussions arose on this topic. I hope people will note Professor G. W. Harris's important comment that too little attention has been paid to protein-binding of adrenal steroids in the blood; possibly measurements of the free non-bound steroid would explain many of the discrepancies in this area of research. The teleological question of what purpose the "short feedback loop" plays in the intact organism is not yet answerable, and raises the further question, "do such short feedback loops exist?"

The second session covered the effects of ACTH and adrenocortical hormones on the nervous system. All the articles in this section favour the concept that pituitary-adrenocortical hormones exert their influence on the central nervous system at different levels, and that their effects on those structures are also deeply involved in the organization of motivated and conditional behavioural reactions.

The third session covered the effects of ACTH and corticosteroids on animal behaviour. Abundant evidence is presented here that endogenous and exogenous ACTH and adrenal corticosteroids can influence both the acquisition and retention of an active or passive avoidance response. ACTH enhances the acquisition and inhibits the extinction of the response, while corticosteroids induce the reverse. The possibility that active polypeptide fragments of ACTH and MSH have behavioural effects raises the important question whether a number of small behaviourally active peptides are produced by the adrenohypophysis. The latter part of the book covers the final session on clinical studies of ACTH, corticosteroids and the brain. This section emphasizes the rapid expansion of research in endocrinology and the relationship with the central nervous system. This degree of interrelation- ship of hormonal and nervous system is so well established that Dr Cleghorn from McGill University points out that this new knowledge must be incorporated in the current knowledge of the informed clinician.

Of particular interest in this section are details that the influence of hormonal excess on growth and development may be to produce a higher IQ, in either the naturally occurring syndrome or those iatrogenically induced by progesterone treatment, in women with threatened abortion. Female issue of such prenatal exposure behave as males. Experiments of this kind could possibly mean pharmacologically induced higher IQ in the future and all its consequences for society. Psychological control of endocrine activity associated with psychotic states is also given in this section.

This book should be read by all neuroendocrinologists, neurophysicists, neurophysiologists and psychiatrists.

DONALD EXLEY

\section{Testis Biochemistry}

The Testis. Edited by A. D. Johnson, W. R. Gomes and N. L. Vandemark. Vol. 2: Biochemistry. Pp. $x v+468$. (Academic: New York and London, September 1970.) $£ 16.35$.

THERE has been for some time, and still is, a real need for a good, comprehensive and advanced text on the biochemistry of the testis, a reference book to which the biochemist and physiologist alike could look for information that is now scattered widely in textbooks, review articles and original papers. During the past decade in particular, progress in the biochemistry of testicular tissue has been rapid and impressive, and has expanded knowledge with respect to several groups of chemical compounds. Among those that have received special attention are the enzymes and steroids. As far as testicular enzymes are concerned, the most outstanding achievements include the purification of hyaluronidase and elucidation of its function; some excellent work on nucleolytic enzymes, especially the nucleotidases ; the equally important advances concerning the mode of action of several phosphokinases and especially those enzymes which accomplish the phosphorylation of nuclear proteins; and in addition, the separation and identification of various kinds of isozymes. Unfortunately, in The Testis hardly any of these accomplishments have received even scant attention, and consequently enzymologists at large will look in vain for answers to the two questions that concern them most-what has been accomplished in the past, and what is worth tackling next? 